\title{
Surgical strategy for huge and advanced hepatocellular carcinoma in Hong Kong
}

\author{
Kenneth S.H. Chok \\ Division of Hepatobiliary and Pancreatic Surgery and Liver Transplantation, Department of Surgery, The University of Hong Kong, Hong Kong, China.
}

Correspondence to: Prof. Kenneth S.H. Chok, Division of Hepatobiliary and Pancreatic Surgery and Liver Transplantation, Department of Surgery, The University of Hong Kong, 102 Pok Fu Lam Road, Hong Kong, China. E-mail: kennethchok@gmail.com

How to cite this article: Chok KSH. Surgical strategy for huge and advanced hepatocellular carcinoma in Hong Kong. Hepatoma Res 2017;3:189-95.

\author{
Article history: \\ Received: 31-07-2017 \\ Accepted: 09-08-2017 \\ Published: 03-09-2017

Key words:
Associating liver partition and
portal vein ligation,
staged hepatectomy,
hepatocellular carcinoma,
liver resection,
vascular resection and
reconstruction,
radiofrequency ablation

\section{INTRODUCTION}

Hepatocellular carcinoma (HCC) is the sixth most common cancer and is the most common primary liver malignancy worldwide. ${ }^{[1]}$ Like hepatitis $B$, it is most prevalent in Asia; at the same time, most cases of $\mathrm{HCC}$ on the continent are related to hepatitis $\mathrm{B}$, and Hong Kong is no exception. ${ }^{[2]}$ Diagnoses of HCC are mostly made at a late stage as regular screening for the disease is uncommon, and the disease often develops in a multifocal manner and infiltrates into major vessels. As such, surgical resection is a common curative treatment. Fan et al. ${ }^{[3]}$ reported 5-year survival rates of $73 \%$ and $81 \%$ achieved by partial hepatectomy and living donor liver transplantation respectively in patients within the Milan criteria.

In the case of huge and advanced HCC, treatment is more limited. Only transarterial chemoembolization (TACE) and systemic therapy are recommended in Western countries, ${ }^{[4-7]}$ but more aggressive management is adopted in Hong Kong. A newly developed Hong Kong liver cancer (HKLC) staging is now in use. In the study by Yau et al., ${ }^{[8]}$ surgery had 
a significant survival benefit over TACE in treating HKLC-2 HCC, with a 5 -year survival of $49 \%$ vs. $0 \%$ $(P<0.001)$; on the other hand, TACE had a significant survival benefit over systemic therapy in treating HKLC-3 HCC, with a 3 -year survival of $10 \%$ vs. $2 \%$ $(P<0.001)$. If the patients are young, fit and properly selected, aggressive resection may still be beneficial despite large or multiple nodules or intrahepatic venous invasion. ${ }^{[8]}$

Disease treatment should be individualized. In general, surgical resection is the core curative treatment for huge and advanced HCC in Hong Kong.

\section{HCCS OF 10 CM OR BIGGER}

Hepatectomy is the first-line HCC treatment for tumor clearance and a cure for patients with preserved liver function. ${ }^{[3,9,10]}$ For HCCs $\geq 10 \mathrm{~cm}$, major hepatectomy is usually needed. Measures to ensure safe major hepatectomy with acceptable complication and perioperative mortality rates include careful patient selection (patients should be fit for surgery and with preserved liver function), ${ }^{[9,11]}$ adoption of the anterior approach to avoid mobilization and rupture of large tumors, ${ }^{[12]}$ close liaison with the anaesthesiologist to ensure a low central venous pressure in order to reduce blood loss, ${ }^{[13]}$ and use of surgical instruments (such as Cavitron Ultrasonic Surgical Aspirator). ${ }^{[9,14-16]}$ Major hepatectomy may not be possible for patients who have marginal liver function or a relatively small future liver remnant (FLR). At our center, we use Indocynaine green (ICG) clearance test to assess preoperative liver function. ${ }^{[17]}$ For consideration for major hepatectomy, an ICG retention rate $\leq 14 \%$ at $15 \mathrm{~min}$ is required. Besides ICG test result, other factors are also taken into account. A low platelet count, poor renal function test results and the presence of significant morbidity can mean a risky major hepatectomy. An adequate FLR with preservation or reconstruction of major hepatic veins and meticulous surgical skills to avoid massive bleeding and vascular insult to the liver are essential to a successful major hepatectomy. ${ }^{[18]}$ FLR is assessed by calculation of the liver volume measured by tracing the liver contour on the cross sectional image on computed tomographic volumetry, and the University of Hong Kong formula is used at our center. ${ }^{[19,20]} \mathrm{A}$ patient's estimated standard liver volume (ESLV) can be derived from the patient's weight, height, and body surface area. ${ }^{[20,21]}$ Patients with liver cirrhosis and relatively poor liver function need a bigger FLR. ${ }^{[22-25]}$ At our center, we use a ratio of FLR/ESLV of $>35 \%$ for major hepatectomy for patients who have Child-Pugh A cirrhosis and an ICG retention rate $\leq 14 \%$ at 15 min. ${ }^{[26]}$ Liver cirrhosis and inadequate FLR are risk factors for postoperative liver failure. ${ }^{[25,27]}$

\section{METHODS TO INCREASE FLR}

In order to increase the chance and safety of major hepatectomy for HCC patients, preoperative portal vein embolization has been used to increase FLR. The idea of portal vein embolization is to embolize (in an open or percutaneous manner) the portal vein ipsilateral to the liver lobe harboring the tumor, so as to induce hypertrophy of the FLR. ${ }^{[28,29]}$ However, it usually takes at least four weeks for the FLR to hypertrophy enough ${ }^{[29]}$ During the time, disease progression may occur. If there is tumor invasion of a major vessel (e.g. the ipsilateral portal vein), the disease can progress in terms of weeks. If contralateral propagation and metastasis develop, the tumor will be inoperable. ${ }^{[30-32]}$ And sometimes hypertrophy does not occur as anticipated.

Associating liver partition and portal vein ligation for staged hepatectomy (ALPPS) is a relatively new method of increasing FLR and is gaining popularity. It features two open operations. In the first operation, liver partition and portal vein ligation are performed to induce hypertrophy of the FLR while no resection is done. When the FLR has hypertrophied enough, the second operation is conducted for tumor resection. ALPPS is particularly useful if there is ipsilateral portal vein tumor thrombosis (PVTT) because the first operation also prevents further propagation of the thrombus into the main and contralateral portal veins. ALPPS was initially applied to relatively normal liver, such as that in the case of colorectal liver metastasis. ${ }^{[33-36]}$ Subsequently its application was extended to steatotic liver and cirrhotic liver. ${ }^{[37-39]}$ With ALPPS, the increase of FLR between the two operations can be as high as $70 \%,{ }^{[40]}$ and it usually takes only one week to achieve enough hypertrophy. ALPPS outperforms conventional portal vein embolization when it comes to time and extent of hypertrophy. ${ }^{[41,42]}$ As the interval between the two operations is not long, adhesion formation resulting from the first operation is relatively immature when the second operation takes place, thereby allowing continuation of dissection and resection of the liver with ease.

However, there is no guarantee that adequate hypertrophy always occur, and liver failure might result from the portal vein ligation. The Pringle maneuver is not advisable as it poses further risk of liver injury. Our center has simplified the ALPPS procedure by using an anterior approach to allow liver transection without mobilization of the right lobe, and as such the amount of adhesion is decreased, thereby streamlining the second operation. ${ }^{[39]}$ The hilar plate and the right hepatic duct are left untouched in the first operation 
to minimize the chance of bile leakage, a complication that might lead to biloma, infection and sepsis and thus prohibit the second operation. ALPPS is a technically demanding and challenging procedure that should not be performed by inexperienced surgeons.

ALPPS should be offered with curative intent when a large tumor load is encountered and a marginal FLR is anticipated. ${ }^{[41]}$ Major vascular invasion, such as portal vein involvement, does not preclude its application. ${ }^{[35]}$ Many patients who would otherwise be unsuitable for major hepatectomy are rendered eligible by ALPPS; the operation rate is thus raised. Nonetheless, the procedure entails higher rates of surgical complication and mortality when compared with conventional major hepatectomy. The reported perioperative mortality rates range from $12 \%$ to $28 \%{ }^{[40,41,43,44]}$ and the complication rate can be as high as $50 \% \cdot{ }^{[43,45]}$ Liver insufficiency (e.g. ascites, persisting cholestasis, sepsis), bile leakage, septic complications and failure to proceed to the second operation have been reported. The long-term outcomes of ALPPS are still pending. Since 2014, 21 patients have undergone ALPPS with curative intent at our center (unpublished data). All of them had R0 resection. No hospital mortality occurred. Three (14\%) patients developed major complications. The overall survival was $89 \%$ and the disease-free survival was $58 \%$ at one year. With time goes by, more data will be available.

\section{INVASION OF THE MAJOR PORTAL VEIN, HEPATIC VEINS, OR THE INFERIOR VENA CAVA}

In the case of ipsilateral PVTT, the thrombus is confined to the liver lobe harboring the $\mathrm{HCC}$ and is usually resected when hepatectomy is conducted to remove the HCC. For the management of PVTT extending to the portal vein bifurcation or farther to the main or contralateral portal vein, different approaches have been advocated. It is believed that en bloc resection (resection of tumor together with all affected parts of the portal vein) can achieve good oncological outcomes with residual microscopic foci removed. Nonetheless, this is a challenging approach since subsequent portal vein reconstruction is required. On the other hand, it has been documented that thrombectomy can yield similar survival outcomes with lower operative mortality and morbidity. ${ }^{[46-48]}$

In a previous study trying to address the controversy about en bloc resection versus thrombectomy, we compared 3 groups of patients: group $1(n=71)$, with ipsilateral PVTT resected in a hepatectomy; group $2(n=10)$, with PVTT extending to or beyond the bifurcation, treated by en bloc resection with portal vein reconstruction; group $3(n=7)$, with PVTT extending to or beyond the bifurcation, treated by thrombectomy. ${ }^{[48]}$ The median survival duration was 10.9 months in group 1, 9.4 months in group 2, and 8.6 months in group 3. No significant differences were found in terms of hospital mortality and morbidity between en bloc resection and thrombectomy. The practice of living donor liver transplantation at our center certainly had contributed to the low morbidity after portal vein resection. ${ }^{[49]}$ The $1-, 3$ - and 5 -year survival rates were $50 \%, 13 \%$ and $13 \%$ respectively in group 2 , and $29 \%, 14 \%$ and $14 \%$ respectively in group 3. The two approaches again showed no significant differences in terms of overall survival and disease-free survival, and patients with ipsilateral PVTT also had similar survival to patients with PVTT extending to or beyond the bifurcation. These survival outcomes are superior when compared with a median of 2.7 months of survival of patients with PVTT not treated. ${ }^{[1]}$

Patients with advanced PVTT may not be suitable for resection due to underlying medical conditions and main portal vein involvement, and non-surgical treatment is their chance. The combination therapy using sorafenib and TACE appears to provide a survival benefit for patients with PVTT and adequate liver function. This benefit seems to be more pronounced in patients whose first-order or more distal branches of the portal vein are involved ${ }^{[50]}$ than in patients with main portal vein involvement. ${ }^{[51]}$ Head-to-head comparison between surgical and non-surgical treatments is warranted.

One point to note is that patients may have falsely elevated preoperative ICG retention rates due to PVTT. Exploration should be offered to patients who fail their ICG test but otherwise show normal liver function. With accumulation of expericence from living donor liver transplantation, resection of major vessels such as portal and hepatic veins should yield satisfactory results.

If the tumor thrombus in the inferior vena cava (IVC) or hepatic vein is non-adhering, thrombectomy should suffice [Figure 1]. Sometimes IVC resection with immediate reconstruction should be considered, especially for young patients. Some technical issues need to be considered when IVC resection with immediate reconstruction is required. First, if the lesion is above the hepatic vein confluence, total vascular exclusion with the Pringle maneuver and re-implantation of the hepatic veins are necessary. Second, it is the lesion's relation to the lower level of the IVC resection (i.e. the renal vein level). In fact, the chance of renal vein invasion is very low. If there is 

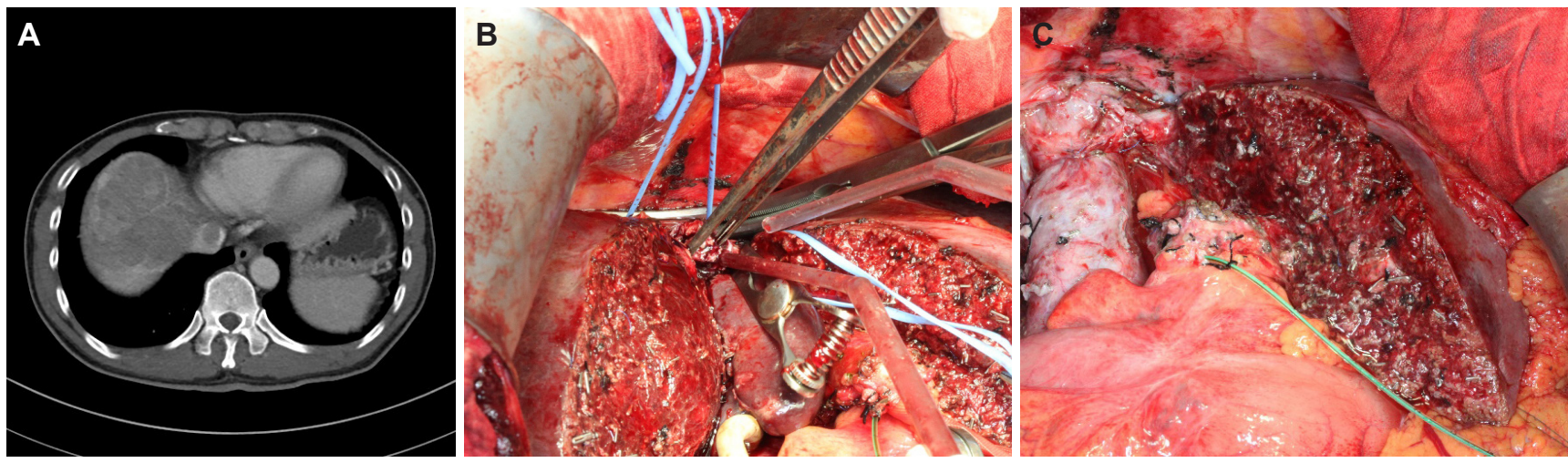

Figure 1: (A) Hepatocellular carcinoma invasion of the suprahepatic inferior vena cava; (B) tumor thrombectomy; (C) closure of the venotomy

invasion of a single renal vein, its resection without reconstruction will not affect normal kidney function. Third, it is the choice of reconstruction conduit. Choices include cadaveric vein graft, autologous vein graft (e.g. renal vein, internal jugular vein) and synthetic graft (e.g. ringed Gore-Tex). At our center, we prefer cadaveric vein graft for it is less rigid and therefore anastomosis will be easier. Nonetheless, its use is limited by availability, blood group compatibility, and length. Length is dictated by donor body size. Usually bench-table work can be done to lengthen a cadaveric IVC graft by incorporating donor bilateral iliac veins. To
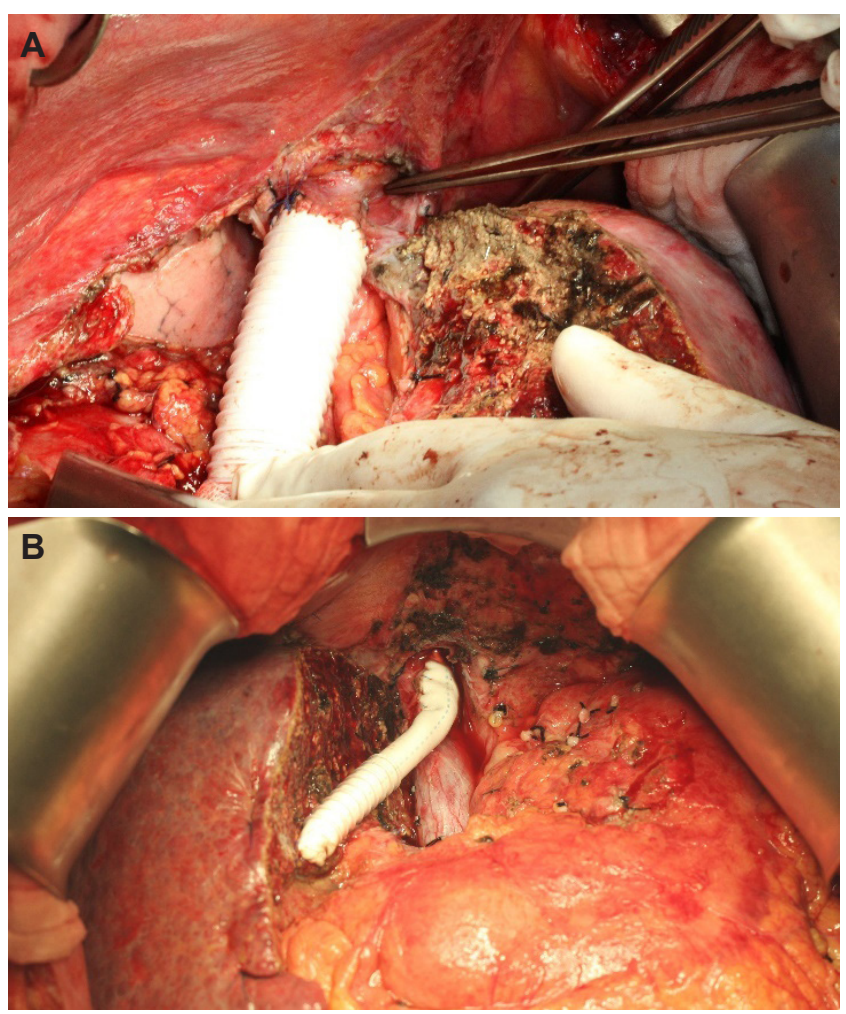

Figure 2: $(A)$ Inferior vena cava reconstruction with a ringed GoreTex graft; $(B)$ middle hepatic vein reconstruction with a ringed Gore-Tex graft avoid creating an additional surgical wound, we prefer not to use autologous vein graft. So, if cadaveric vein graft is not available, a ringed Gore-Tex graft is used [Figure 2].

If the tumor thrombus extends above the diaphragm, a cardiopulmonary bypass by cardiac surgeon may be necessary for its complete removal. However, before considering this high-risk procedure, aggressive workup must be done to rule out other extrahepatic spread of disease, and the treatment approach should be thoroughly discussed with the patient.

\section{BILOBAR INVOLVEMENT}

For selected patients with bilobar HCC, the combination of resection and radiofrequency ablation can offer a cure. Cheung et al. ${ }^{[52]}$ compared 19 patients having such a combination of treatments with 54 patients having resection only. Fourteen (74\%) patients in the combination group and $3(6 \%)$ patients in the resection group had bilobar involvement $(P=0.04)$. Major resection was performed in $6(32 \%)$ patients in the combination group and $35(65 \%)$ patients in the resection group, whereas minor resection was performed in $13(68 \%)$ and $19(35 \%)$ patients in the combination group and resection group respectively $(P=0.012)$. The combination group had less blood loss (400 vs. $657 \mathrm{~mL}, P=0.007$ ), shorter operation (270 vs. $400 \mathrm{~min}, P=0.001$ ), and shorter hospital stay ( 7 vs. 8.5 days, $P=0.042$ ). The two groups were comparable in hospital mortality $(5 \%$ vs. $6 \%, P=1)$, surgical complication ( $16 \%$ vs. $32 \%, P=0.24)$, disease recurrence $(63 \%$ vs. $50 \%, P=0.673)$, and overall survival (53 vs. 44.5 months, $P=0.496$ ). Thorough intraoperative assessment backed by a sound understanding of the liver anatomy helps to maximize the chance of cure for patients with bilobar HCC. 


\section{DOWNSTAGING}

Both TACE and radioembolization are safe and effective in highly selected patients. Radioembolization may confer a survival benefit over sorafenib on advancedstage patients. Radioembolization is preferable to TACE for advanced-stage patients, especially those with macrovascular invasion, since TACE might induce liver failure. ${ }^{[53]}$ However, the effectiveness of downstaging is not conclusive, as most of the cases reported were limited by poor underlying liver function.

\section{EXTRAHEPATIC METASTASIS}

Lung is the most common site for extrahepatic metastasis of HCC. ${ }^{[54]}$ A previous study by our center reported that metastasectomy conferred a survival benefit on HCC patients who developed lung metastasis after hepatectomy. ${ }^{[5]}$ Overall survival was compared in patients with resectable and unresectable lung metastases and in two periods (Era 1: 1989-1995, Era 2: 1996-2010). The median survival duration of patients with resectable and unresectable disease was 40.4 and 7.5 months respectively $(P<$ 0.0001). In Era 1, the median survival duration of patients with resectable and unresectable disease was 43.2 and 5.6 months respectively $(P<0.0001)$. The corresponding figures in Era 2 were 32.9 and 8.4 months $(P<0.0001)$. Survival of patients with resectable disease did not differ significantly in the two periods but there was a significant improvement in survival of patients with unresectable disease in Era 2. Their 1-, 3- and 5-year survival rates in Era 1 vs. Era 2 were $11 \%$ vs. $38 \%, 6 \%$ vs. $9 \%$, and $3 \%$ vs. $4 \%$, respectively $(P=0.041)$. The corresponding figures in their counterparts were $90 \%$ vs. $86 \%, 80 \%$ vs. $46 \%$, and $40 \%$ vs. $30 \%$, respectively $(P=0.443)$. Whenever possible, metastasectomy for pulmonary metastases of HCC should be offered to medically fit patients.

\section{CONCLUSION}

Although huge and advanced HCC is deadly, surgical treatment in properly selected patients is still feasible with acceptable risks. In recent years, there are revolutional changes in surgical techniques together with new strategies to enhance the resectability of this fatal disease. Ways to increase FLR and improvements in surgical techniques allow more patients to benefit from surgical resection even in the presence of cirrhosis and major vascular invasion. Adjunctive use of radiofrequency ablation for bilobar involvement and selective use of metastasectomy for extrahepatic metastasis have been shown to be effective. Optimal treatment modalities are still evolving. ALPPS will continue to be developed and more long-term results will be available in the near future.

\section{DECLARATIONS}

\section{Authors' contributions}

K.S.H. Chok contributed solely to this paper.

\section{Financial support and sponsorship}

None.

\section{Conflicts of interest}

The author has no conflicts of interest with regard to the study or its publication.

\section{Patient consent}

Not applicable.

\section{Ethics approval}

Not applicable.

\section{REFERENCES}

1. Kim DY, Han KH. Epidemiology and surveillance of hepatocellular carcinoma. Liver Cancer 2012;1:2-14.

2. Ferlay J, Shin HR, Bray F, Forman D, Mathers C, Parkin DM Estimates of worldwide burden of cancer in 2008: GLOBOCAN 2008. Int J Cancer 2010;127:2893-917.

3. Fan ST, Poon RT, Yeung C, Lam CM, Lo CM, Yuen WK, Ng KK, Liu $\mathrm{CL}$, Chan SC. Outcome after partial hepatectomy for hepatocellular cancer within the Milan criteria. Br J Surg 2011;98:1292-300.

4. Llovet JM, Bru C, Bruix J. Prognosis of hepatocellular carcinoma: the BCLC staging classification. Semin Liver Dis 1999;19:329-38.

5. Bruix J, Llovet JM. Prognostic prediction and treatment strategy in hepatocellular carcinoma. Hepatology 2002;35:519-24.

6. Llovet JM, Burroughs A, Bruix J. Hepatocellular carcinoma. Lancet 2003;362:1907-17.

7. Forner A, Reig ME, de Lope CR, Bruix J. Current strategy for staging and treatment: the BCLC update and future prospects. Semin Liver Dis 2010;30:61-74.

8. Yau T, Tang VY, Yao TJ, Fan ST, Lo CM, Poon RT. Development of Hong Kong Liver Cancer staging system with treatment stratification for patients with hepatocellular carcinoma. Gastroenterology 2014;146:1691-700.e3.

9. Fan ST, Mau Lo C, Poon RT, Yeung C, Leung Liu C, Yuen WK Ming Lam C, Ng KK, Ching Chan S. Continuous improvement of survival outcomes of resection of hepatocellular carcinoma: a 20-year experience. Ann Surg 2011;253:745-58.

10. Cauchy F, Soubrane O, Belghiti J. Liver resection for HCC: patient's selection and controversial scenarios. Best Pract Res Clin Gastroenterol 2014;28:881-96.

11. Poon RT, Fan ST. Assessment of hepatic reserve for indication of hepatic resection: how I do it. $J$ Hepatobiliary Pancreat Surg 2005;12:31-7.

12. Liu CL, Fan ST, Cheung ST, Lo CM, Ng IO, Wong J. Anterior approach versus conventional approach right hepatic resection for large hepatocellular carcinoma: a prospective randomized controlled 
study. Ann Surg 2006;244:194-203.

13. Melendez JA, Arslan V, Fischer ME, Wuest D, Jarnagin WR, Fong Y, Blumgart LH. Perioperative outcomes of major hepatic resections under low central venous pressure anesthesia: blood loss, blood transfusion, and the risk of postoperative renal dysfunction. J Am Coll Surg 1998;187:620-5.

14. Fan ST, Lai EC, Lo CM, Ng IO, Wong J. Hospital mortality of major hepatectomy for hepatocellular carcinoma associated with cirrhosis. Arch Surg 1995;130:198-203.

15. Poon RT, Fan ST, Lo CM, Liu CL, Lam CM, Yuen WK, Yeung C, Wong J. Extended hepatic resection for hepatocellular carcinoma in patients with cirrhosis: is it justified? Ann Surg 2002;236:602-11.

16. Fan ST, Lo CM, Liu CL, Lam CM, Yuen WK, Yeung C, Wong J. Hepatectomy for hepatocellular carcinoma: toward zero hospital deaths. Ann Surg 1999;229:322-30.

17. Lau H, Man K, Fan ST, Yu WC, Lo CM, Wong J. Evaluation of preoperative hepatic function in patients with hepatocellular carcinoma undergoing hepatectomy. Br J Surg 1997;84:1255-9.

18. Fan ST. Liver functional reserve estimation: state of the art and relevance for local treatments: the Eastern perspective. J Hepatobiliary Pancreat Surg 2010;17:380-4.

19. Heymsfield SB, Fulenwider T, Nordlinger B, Barlow R, Sones P, Kutner M. Accurate measurement of liver, kidney, and spleen volume and mass by computerized axial tomography. Ann Intern Med 1979;90:185-7.

20. Chan SC, Lo CM, Chok KS, Sharr WW, Cheung TT, Tsang SH, Chan AC, Fan ST. Validation of graft and standard liver size predictions in right liver living donor liver transplantation. Hepatol Int 2011;5:913-7.

21. Urata K, Kawasaki S, Matsunami H, Hashikura Y, Ikegami T, Ishizone S, Momose Y, Komiyama A, Makuuchi M. Calculation of child and adult standard liver volume for liver transplantation. Hepatology 1995;21:1317-21.

22. Shoup M, Gonen M, D'Angelica M, Jarnagin WR, DeMatteo RP, Schwartz LH, Tuorto S, Blumgart LH, Fong Y. Volumetric analysis predicts hepatic dysfunction in patients undergoing major liver resection. J Gastrointest Surg 2003;7:325-30.

23. Vauthey JN, Chaoui A, Do KA, Bilimoria MM, Fenstermacher MJ, Charnsangavej C, Hicks M, Alsfasser G, Lauwers G, Hawkins IF, Caridi J. Standardized measurement of the future liver remnant prior to extended liver resection: methodology and clinical associations. Surgery 2000;127:512-9.

24. Kubota K, Makuuchi M, Kusaka K, Kobayashi T, Miki K, Hasegawa K, Harihara Y, Takayama T. Measurement of liver volume and hepatic functional reserve as a guide to decision-making in resectional surgery for hepatic tumors. Hepatology 1997;26:1176-81.

25. Shirabe K, Shimada M, Gion T, Hasegawa H, Takenaka K, Utsunomiya T, Sugimachi K. Postoperative liver failure after major hepatic resection for hepatocellular carcinoma in the modern era with special reference to remnant liver volume. $J$ Am Coll Surg 1999;188:304-9.

26. Guglielmi A, Ruzzenente A, Conci S, Valdegamberi A, Iacono C. How much remnant is enough in liver resection? Digest Surg 2012;29:6-17.

27. Schindl MJ, Redhead DN, Fearon KC, Garden OJ, Wigmore SJ; Edinburgh Liver Surgery and Transplantation Experimental Research Group (eLISTER). The value of residual liver volume as a predictor of hepatic dysfunction and infection after major liver resection. Gut 2005;54:289-96.

28. Kinoshita H, Sakai K, Hirohashi K, Igawa S, Yamasaki O, Kubo S. Preoperative portal vein embolization for hepatocellular carcinoma. World J Surg 1986;10:803-8.

29. Abulkhir A, Limongelli P, Healey AJ, Damrah O, Tait P, Jackson J, Habib N, Jiao LR. Preoperative portal vein embolization for major liver resection: a meta-analysis. Ann Surg 2008;247:49-57.
30. Heinrich S, Jochum W, Graf R, Clavien PA. Portal vein ligation and partial hepatectomy differentially influence growth of intrahepatic metastasis and liver regeneration in mice. $J$ Hepatol 2006;45:35-42.

31. Elias D, De Baere T, Roche A, Mducreux, Leclere J, Lasser P. During liver regeneration following right portal embolization the growth rate of liver metastases is more rapid than that of the liver parenchyma. $\mathrm{Br}$ J Surg 1999;86:784-8.

32. Kokudo N, Tada K, Seki M, Ohta H, Azekura K, Ueno M, Ohta K, Yamaguchi T, Matsubara T, Takahashi T, Nakajima T, Muto T, Ikari T, Yanagisawa A, Kato Y. Proliferative activity of intrahepatic colorectal metastases after preoperative hemihepatic portal vein embolization. Hepatology 2001;34:267-72.

33. Schadde E, Ardiles V, Robles-Campos R, Malago M, Machado M, Hernandez-Alejandro R, Soubrane O, Schnitzbauer AA, Raptis D, Tschuor C, Petrowsky H, De Santibanes E, Clavien PA; ALPPS Registry Group. Early survival and safety of ALPPS: first report of the International ALPPS Registry. Ann Surg 2014;260:829-38.

34. Cavaness KM, Doyle MB, Lin Y, Maynard E, Chapman WC. Using ALPPS to induce rapid liver hypertrophy in a patient with hepatic fibrosis and portal vein thrombosis. J Gastrointest Surg 2013;17:20712.

35. Vennarecci G, Laurenzi A, Santoro R, Colasanti M, Lepiane P, Ettorre GM. The ALPPS procedure: a surgical option for hepatocellular carcinoma with major vascular invasion. World J Surg 2014;38:1498503.

36. Vennarecci G, Laurenzi A, Levi Sandri GB, Busi Rizzi E, Cristofaro M, Montalbano M, Piselli P, Andreoli A, D’Offizi G, Ettorre GM. The ALPPS procedure for hepatocellular carcinoma. Eur J Surg Oncol 2014;40:982-8.

37. Levi Sandri GB, Lai Q, Rayar M, Sulpice L. ALPPS procedure for hepatocellular carcinoma with macrovascular thrombosis: a new opportunity? J Hepatol 2015;62:241-2.

38. Baumgart J, Lang S, Lang H. A new method for induction of liver hypertrophy prior to right trisectionectomy: a report of three cases. HPB (Oxford) 2011;13:71-2.

39. Chan AC, Pang R, Poon RT. Simplifying the ALPPS procedure by the anterior approach. Ann Surg 2014;260:e3.

40. Schnitzbauer AA, Lang SA, Goessmann H, Nadalin S, Baumgart J, Farkas SA, Fichtner-Feigl S, Lorf T, Goralcyk A, Hörbelt R, Kroemer A, Loss M, Rümmele P, Scherer MN, Padberg W, Königsrainer A, Lang H, Obed A, Schlitt HJ. Right portal vein ligation combined with in situ splitting induces rapid left lateral liver lobe hypertrophy enabling 2-staged extended right hepatic resection in small-for-size settings. Ann Surg 2012;255:405-14.

41. Schadde E, Ardiles V, Slankamenac K, Tschuor C, Sergeant G, Amacker N, Baumgart J, Croome K, Hernandez-Alejandro R, Lang $H$, de Santibaňes E, Clavien PA. ALPPS offers a better chance of complete resection in patients with primarily unresectable liver tumors compared with conventional-staged hepatectomies: results of a multicenter analysis. World J Surg 2014;38:1510-9.

42. Ielpo B, Quijano Y, Vicente E. Pearls and pitfalls on ALPPS procedure: new complications in a new technique. Updates Surg 2014;66:159-61.

43. Nadalin S, Capobianco I, Li J, Girotti P, Konigsrainer I, Konigsrainer A. Indications and limits for associating liver partition and portal vein ligation for staged hepatectomy (ALPPS). Lessons learned from 15 cases at a single centre. Z Gastroenterol 2014;52:35-42.

44. Knoefel WT, Gabor I, Rehders A, Alexander A, Krausch M, Schulte am Esch J, Fürst G, Topp SA. In situ liver transection with portal vein ligation for rapid growth of the future liver remnant in two-stage liver resection. Br J Surg 2013;100:388-94.

45. Schadde E, Schnitzbauer AA, Tschuor C, Raptis DA, Bechstein 
WO, Clavien PA. Systematic review and meta-analysis of feasibility, safety, and efficacy of a novel procedure: associating liver partition and portal vein ligation for staged hepatectomy. Ann Surg Oncol 2015;22:3109-20.

46. Wu CC, Hsieh SR, Chen JT, Ho WL, Lin MC, Yeh DC, Liu TJ, P'eng FK. An appraisal of liver and portal vein resection for hepatocellular carcinoma with tumor thrombi extending to portal bifurcation. Arch Surg 2000;135:1273-9.

47. Tanaka A, Morimoto T, Yamaoka Y. Implications of surgical treatment for advanced hepatocellular carcinoma with tumor thrombi in the portal vein. Hepatogastroenterology 1996;43:637-43.

48. Chok KS, Cheung TT, Chan SC, Poon RT, Fan ST, Lo CM. Surgical outcomes in hepatocellular carcinoma patients with portal vein tumor thrombosis. World J Surg 2014;38:490-6.

49. Chan SC, Liu CL, Lo CM, Lam CM, Poon RT, Yuen WK, Fan ST, Wong J. Value of live donor liver transplantation experience in major hepatectomy for hepatocellular carcinoma. Arch Surg 2003;138:265-71.

50. Zhu K, Chen J, Lai L, Meng X, Zhou B, Huang W, Cai M, Shan H.
Hepatocellular carcinoma with portal vein tumor thrombus: treatment with transarterial chemoembolization combined with sorafenib--a retrospective controlled study. Radiology 2014;272:284-93.

51. Ha Y, Lee D, Shim JH, Lim YS, Lee HC, Chung YH, Lee YS, Park SR, Ryu MH, Ryoo BY, Kang YK, Kim KM. Role of transarterial chemoembolization in relation with sorafenib for patients with advanced hepatocellular carcinoma. Oncotarget 2016;7:74303-13.

52. Cheung TT, Ng KK, Chok KS, Chan SC, Poon RT, Lo CM, Fan ST. Combined resection and radiofrequency ablation for multifocal hepatocellular carcinoma: prognosis and outcomes. World $J$ Gastroenterol 2010;16:3056-62.

53. Kishore S, Friedman T, Madoff DC. Update on embolization therapies for hepatocellular carcinoma. Curr Oncol Rep 2017;19:40.

54. Lee YT, Geer DA. Primary liver cancer: pattern of metastasis. $J$ Surg Oncol 1987;36:26-31.

55. Chok KS, Yau TC, Cheung TT, Poon RT, Lo CM. Retrospective study of metachronous lung metastases from primary hepatocellular carcinoma. ANZ J Surg 2016;86:289-93. 